\title{
ESCRITAS DE AUTORIA FEMININA: CONTOS ASSINALADOS PELO NÃO-DITO
}

\author{
Maria Andréia de Paula Silva ${ }^{1}$ \\ Emânia Aparecida Rodrigues Gonçalves ${ }^{2}$ \\ Luciana Genevan da Silva Dias Ferreira ${ }^{3}$
}

\begin{abstract}
RESUMO: Contos escritos por Nélida Piñon, Orlanda Amarílis e Lídia Jorge, escritoras lusófonas, oportunizam uma abordagem crítica sobre discursos e espaços femininos enunciados e encenados na literatura de língua portuguesa do final do século XX. O embasamento teórico do trabalho pauta-se, principalmente, em Simone de Beauvoir (1970), sobre o feminino, em Gayatri Spivak (2010), sobre a representação da subalternidade, em Pierre Bourdieu (2002) sobre a violência.
\end{abstract}

Palavras-chave: Feminino. Silenciamento. Violência.

\section{Introdução}

Elaborações da linguagem ficcional que captam instantes fragmentados de episódios narrados com intensidade e tensão, contos escritos por Nélida Piñon, Orlanda Amarílis e Lídia Jorge, escritoras lusófonas, oportunizam uma abordagem crítica sobre discursos e espaços femininos enunciados e encenados na literatura de língua portuguesa do final do século XX. As obras literárias, objetos deste estudo, denominam-se $O$ calor das coisas (1980), de Nélida Piñon, A casa dos mastros (1989), de Orlanda Amarílis, Marido e outros contos (1997), de Lídia Jorge. Dentre os contos que compõem cada uma das três coletâneas, enfatizam-se "I Love my Husband", contido em $O$ calor das coisas (1980), de Piñon, "A casa dos mastros", conto homônimo dessa obra ficcional de Amarílis, e "Marido", narrativa presente na obra Marido e outros contos (1997), de Jorge.

Essas três narrativas ficcionais, escritas por uma brasileira, uma cabo-verdiana e uma portuguesa, promovem discussões e reflexões sobre paradigmas sociais construídos por culturas androcêntricas, que pontuam condutas, convicções e hábitos que concebem o feminino como subordinado ao masculino e, sendo assim, naturalizam a violência contra a mulher, o que, por conseguinte, gera uma cultura de indulgência com este tipo de violência. A violência contra a mulher tangencia o abjeto. Essa circunstância de abjeção desorganiza a subjetividade feminina que precisa constantemente ser repensada. A ficção é uma dentre as possibilidades de se refletir sobre a violência real (abjeta) contra a mulher, pois o texto ficcional se refere à realidade sem se esgotar nesta referência, isto é, o fictício repete a realidade de modo a encenar o que é representado no mundo (ISER, 2002).

Nélida Piñon, Orlanda Amarílis e Lídia Jorge, por meio da ficção, promovem diálogos entre questões sociais, políticas e históricas bem como decorrentes implicações tanto de discursos (não) produzidos quanto de espaços (não) ocupados pelo feminino nesses contextos, por causa do silenciamento e da invisibilidade da mulher. Essas narrativas, escritas nas décadas finais do século XX, por penas femininas lusófonas, revelam contextos que, vivenciados por personagens ficcionais, marcam a presença de violência simbólica e também física no cotidiano da mulher, bem como na literatura de autoria feminina.

\footnotetext{
${ }^{1}$ Doutora em Letras, pela Universidade Federal de Juiz de Fora, professora do Centro de Ensino Superior de Juiz de Fora (CES/JF). E-mail: mariaandreiasilva@cesjf.br

2 Doutoranda em Letras, Estudos Literários, pelo Programa de Pós-Graduação da Faculdade de Letras da Universidade Federal de Juiz de Fora. Mestre em Letras pelo Centro de Ensino Superior de Juiz de Fora. Graduada em Letras pela Universidade Federal de Juiz de Fora. E-mail: emaniarodrigues@yahoo.com.br.

${ }^{3}$ Doutoranda em Letras, Literaturas de Língua Portuguesa, pela Pontifícia Universidade Católica de Minas Gerais. Bolsista FAPEMIG. Mestre em Letras pelo Centro de Ensino Superior de Juiz de Fora. Graduada em Letras pela Universidade Federal de Juiz de Fora. E-mail: luciana.genevan@ gmail.com
}

IPOTESI, JUIZ DE FORA, v.23, n.1, p. 113-120, jan./jun. 2019 
A lusofonia se configura, nesta abordagem, como comarca desterritorializada que estabelece o elo entre as obras de Piñon, Amarílis e Jorge, já que a língua portuguesa, imposta pelo colonizador europeu, institui, na diferença, identidades entre Portugal, Brasil e Cabo Verde, aquele, explorador, e estes, colônias (DELEUZE; GATTARI, 1972). A língua torna-se um espaço constituído de palavras que circulam no idioma, o qual abarca literaturas, transbordando-as (LUDMER, 2010). Para Benjamin Abdala Júnior, "a própria veiculação linguística em português é base contextual para uma atualização diferenciada, quando os textos veiculados são objeto de apreensão e de transformação em cada país" (ABDALA JÚNIOR, 2003, p. 111).

Ressalta-se, no entanto, que apesar de haver, conforme Abdala Júnior, "uma campo comum de contatos entre esses sistemas literários nacionais que [enredam] historicamente constantes semelhanças da série ideológica", os caracteres de subjetivação e de submissão femininos diferem-se em decorrência dos contextos sociais, políticos, históricos, culturais e econômicos de cada país: Portugal, Brasil e Cabo Verde (ABDALA JÚNIOR, 1989, p. 16). Enquanto em Portugal, país inserido no contexto ocidental europeu, há uma perspectiva, conforme assinala Michel Foucault, vinculada à ótica greco-romana, que ecoa mesmo (ainda) no século XX, segundo a qual o feminino subordina-se ao poder do outro (pai, marido, tutor), em países colonizados como Brasil e Cabo Verde a ideologia patriarcal se alia à opressão imposta pelo colonialismo (FOUCALT, 1994b).

O Brasil, no entanto, à época em que se contextualizam as obras literárias em pauta, encontrava-se mais distante do subjugo lusitano, já que se torna independente de Portugal no primeiro quarto do século XIX, passava por um momento de extrema violência decorrente do regime militar que se estendeu entre os anos de 1960, 1970 e metade de 1980. Já Cabo Verde, país insular, torna-se independente da opressão portuguesa apenas no último quarto do século XX, portanto, em 1989, época de publicação do conto de Amarílis aqui analisado, o país ainda está se elaborando como emancipado. Esses vínculos históricos entre os três países estabelecem tanto laços quanto nós em espaços literários de escritas de mulheres, podendo implicar em maior ou menor grau de silenciamento feminino, bem como de retenção discursiva.

Alinham-se, porém, essas escritas de mulheres por narrar histórias cuja temática aborda a violência sofrida por personagens femininas subalternas em espaços domésticos periféricos. A subalternidade do feminino é uma questão cara a Gayatri Chakravorty Spivak, pois segundo essa teórica "a mulher subalterna encontra-se em uma posição ainda mais periférica pelos problemas subjacentes às questões de gênero" (SPIVAK, 2010, p. 69 apud ALMEIDA, 2010, p. 14-15). Sendo assim, essas três intelectuais assumem a tarefa de escrever sobre o feminino, mostrando, por meio da ficção, o silenciamento da mulher em espaços continentais e insular diversos, os quais convergem para periferias.

Essas figuras femininas se constituem como seres ficcionais que não possuem representação política tampouco legal nesses espaços, por isso são privadas da possibilidade de se tornarem integrantes do estrato social dominante. Além disso, configuram-se, também, como personagens protagonistas cujo caráter dialógico na fala é ausente, sendo esse mais um aspecto da subalternização (SPIVAK, 2010).

Às semelhanças da temática e dos elementos narrativos dos três contos, soma-se a possibilidade de criar, na ficção escrita por mulheres-intelectuais, espaços e condições para falar da (ou pela) mulher subalterna, já que segundo Spivak: "O subalterno não pode falar. Não há valor algum atribuído à 'mulher' como item respeitoso nas listas de prioridades globais" (SPIVAK, 2010, p. 126, grifos da autora). Desse modo, a língua portuguesa, a autoria de gênero feminino, o conteúdo temático da violência e a forma literária do gênero conto unem essas três obras ficcionais: O calor das coisas (1980), de Nélida Piñon, A casa dos mastros (1989), de Orlanda Amarílis, Marido e outros contos (1997), de Lídia Jorge. 
A partir dessas narrativas ficcionais curtas, de autoria feminina, analisa-se a construção de discursos e de espaços sobre/para o feminino, buscando pontos de interseção entre forma e conteúdo, por meio de recursos literários de contos que narram a violência do/no discurso feminino retido. Estudar as personagens femininas, em seu potencial de protagonistas (in)conformadas com o ambiente de atuação, possibilita uma analogia entre subjetividade e coisificação do feminino.

Além disso, essas obras de Nélida Piñon, Orlanda Amarílis e Lídia Jorge suscitam análise crítico-literária que dialoga com outras áreas do conhecimento, sendo relevante uma pesquisa que traga à discussão questões sociológicas, políticas e históricas, buscando compreendê-las a partir dos pressupostos de seu gênero textual e das circunstâncias contextuais de sua produção. Além de possibilitar, conforme Spivak, reflexão teórica sobre a "imagem da mulher" e o silêncio do feminino, assinalados por mulheres-intelectuais (SPIVAK, 2010, p. 66).

\section{Vozes femininas silenciadas?}

Narrativas ficcionais curtas, os contos de Nélida Piñon, Orlanda Amarílis e Lídia Jorge, intitulados, respectivamente, "I Love my Husband", "A casa dos Mastros" e "Marido", questionam as narrativas ocidentais que estabelecem o masculino como centro da cultura, ao articularem as diferenças de gênero como categoria de análise histórica e a heterogeneidade de vozes configuradas na tessitura literária. Soma-se, ao conteúdo recalcitrante, a forma literária, pois são narrativas que se distanciam dos cânones convencionados pelo Ocidente, quais sejam, sobretudo, romances de autoria masculina quando se pensa em prosa ficcional.

Os contos "I Love my Husband", "A casa dos Mastros" e "Marido" foram escritos nas últimas décadas do século passado, por Nélida Piñon, Orlanda Amarílis e Lídia Jorge, respectivamente, e enunciam histórias de personagens protagonistas que representam mulheres que foram criadas e educadas de acordo com os padrões rígidos das sociedades patriarcais lusófonas do século XX. Mas as autoras conseguem pontuar, por meio de construções discursivas, o plurilinguismo nas narrativas, para questionar o paradigma de dominação masculina vigente nas sociedades da época e que se estende aos nossos dias, tornando-se relevante a análise crítica dessas obras (BAKTHIN, 1993).

Nas ficções em análise, destacam-se características do feminino construídas conforme uma ideologia de submissão da mulher, que vigorou em espaços ocidentais durante todo o século XX e se estende até a atualidade. As três escritoras, no entanto, apresentam críticas a essa configuração ideológica de submissão feminina, ao abordar personagens femininas que têm discursos retidos por estratégias narrativas do gênero literário denominado conto, demonstrando a violência não só contra a mulher, mas também contra o direito de fala desses sujeitos.

Sobre supostas passividade e submissão do feminino, observadas nos contos em análise, por meio das personagens que encenam as esposas, em "I Love my Husband" e em "Marido", e da personagem que representa uma possível futura esposa, em "A casa dos Mastros", recorreu-se à abordagem de Simone de Beauvoir, que explica, na obra O Segundo Sexo: fatos e mitos (1970), a provável constituição dessa categoria nas obras ficcionais, ao pontuar que, na sociedade, o feminino é constituído conforme ideologia dominante masculina, como se vê na afirmativa seguinte:

[...] na mulher há, no início, um conflito entre a sua existência autónoma e o seu 'ser-outro'; ensinam-lhe que para agradar é preciso procurar agradar, fazer-se objeto; ela deve, portanto, renunciar à sua autonomia. (BEAUVOIR, 1970, p. 22, grifos da autora). 
As personagens que encenam as esposas, nos contos de Pinõn e Jorge, e futura esposa, na narrativa de Amarílis, protagonistas das ficções em análise, simbolizam a submissão da mulher ao marido ou ao pai, em sociedades patriarcais. Enquanto a personagem que encena a esposa em "I Love my Husband", inominada, não consegue conversar com o marido, pois ele não considera suas questões individuais relevantes, Violete, protagonista de "A casa dos Mastros", é abandonada pelo noivo ao expor suas questões pessoais, e, por sua vez, Lúcia, a porteira do conto "Marido", espera emudecida, diariamente, o retorno do esposo a casa, rezando, por temer que ele chegue alcoolizado e violento. Todas sofrem a violência simbólica, mas as personagens Violete e Lúcia também sofrem a violência física.

Por meio dos campos semânticos dos sintagmas verbais, grunhir e vociferar, em "I Love my Husband", devorar e castigar, em "A casa dos Mastros", e proteger e abafar, em "Marido", de Lídia Jorge, evidencia-se o feminino como o espaço da submissão, isto é, o espaço saturado de violência mascarada de normalidade. No espaço-temporal cotidiano, as personagens femininas, representadas nos contos, sofrem restrições impostas pelos outros, sobretudo, limitações de palavras, ou seja, discursos retidos, fragmentados, silenciados, característicos do gênero literário conto, porque em contos há compressão/ retenção dos fatos narrados (CORTÁZAR, 2006). A esposa inominada do conto "I Love my Husband" demonstra alguns questionamentos quanto à condição estabelecida para a mulher no casamento, mas não rompe com essa condição efetivamente, a não ser por meio de devaneios. Violete, personagem que não se casa, sofre as consequências e violências de permanecer solteira. E Lúcia, por sua vez, silencia-se.

A instância narrativa, em "Marido", acentua o caráter de sujeição de Lúcia, consequentemente do feminino na obra, ao caracterizá-la como doce e ao assinalar que ela perdeu a doçura "sem o mostrar, exactamente [sic] porque era doce" quando notou que os habitantes do prédio onde reside e trabalha criticavam a conduta do marido (JORGE, 1998, p. 17). A partir do momento em que os vizinhos interferem em sua vida conjugal, a porteira isola-se, afasta-se deles, porque a queriam orientar. A personagem Lúcia encena o feminino oprimido. A porteira não considera a possibilidade de uma separação, por isso contenta-se, em tese, com a manutenção do casamento, exaltando o marido e relevando seu comportamento quando está embriagado, conforme se observa no trecho que segue: "[...] fora da bebida nunca tinha querido bater nem matar, como tantos há", (JORGE, 1998, p. 19). Já a esposa de "I Love my Husband", apesar de ensaiar tentativas de diálogos com o marido, não consegue alterar o seu lugar de submissão feminina, como se verifica no trecho que segue: "Empenho-me em agradá-lo, ainda que sem vontade às vezes [...] (PIÑON, 1980, p.67). E Violete, apesar de não se casar, não sofrendo, portanto, as violências decorrentes do casamento, tolera, ainda assim, o subjugo patriarcal, pois sofre violência sexual em casa, cujos autores são o primo e o próprio pai, e na igreja, cujo autor é o padre.

Lúcia convive com a violência e, para se livrar de possíveis agressões, esconde-se do marido nas noites em que ele chega ébrio, procurando-a pela casa até cair e adormecer no chão, consoante se verifica no excerto que segue: "com as pernas abertas, caía no chão, perdia a rigidez das pernas e dormia, no meio da casa para onde ela voltava" (JORGE, 1998, p. 20). Também a esposa do conto "I Love my Husband", desde o nascimento, vive sob a égide da opressão masculina (BOURDIE, 2002). Primeiramente, até o casamento, ela vive sob o domínio do pai; depois do casamento, ela vive sob o domínio do marido. Ela jamais teve autonomia ou liberdade durante sua vida. Do mesmo modo, Violete sofre as consequências do sistema patriarcal, sendo abusada sexualmente por três homens.

O silêncio da personagem Lúcia e as poucas palavras proferidas ao marido pela esposa de "I Love my Husband" e por Violete aos demais personagens de "A casa dos Mastros" são estratégias que as autoras utilizam para pontuar o discurso feminino retido. $\mathrm{O}$ feminino, em 
Nélida Piñon, Orlanda Amarílis e Lídia Jorge, é um conceito que rompe com as definições semânticas de fragilidade e emotividade, pois apesar de as autoras construírem-no conforme campos semânticos de dominação masculina, as personagens libertam-se da opressão, uma por meio do devaneio, outra por meio da leitura e outra por meio da morte.

Quanto à forma, na linguagem narrativa, o feminino, em "I Love my Husband", de Piñon, seria invocado por vozes sociais presentes na ficção que questionam a condição da mulher, por meio da língua do dominador. Em "A casa dos mastros", de Amarílis, comprimem-se forma linguística e conteúdo, representados inclusive pelo nome da protagonista, que tem em seu radical a violência escrita, \{Viol-\}, Violete/ violência, etimologicamente, do latim violentia (RESENDE, 1996). Em "Marido", obra de Jorge, o feminino é trazido por meio da oração explodida e oralizada, que pontua a insubmissão.

Os contos "I Love my Husband", de Nélida Piñon, "A casa dos mastros", de Orlanda Amarílis, e "Marido", de Lídia Jorge, sinalizam a violência como componente temático e estético dos textos, cujas formas provocam, denunciam e promovem estranheza e embaraço, porque, ao mesmo tempo e paradoxalmente, rompem e também reforçam o senso comum que considera o casamento como um espaço de relações familiares e de violência. As três obras ficcionais abordam a violência na forma e no conteúdo, mas se duas, "A casa dos mastros" e "Marido", de Amarílis e Jorge, respectivamente, explicitam a violência física, outra, "I Love my Husband", de Piñon, evidencia a violência simbólica (BOURDIEU, 2002).

Desse modo, a encenação da violência não tem, nesses contextos ficcionais, caráter laudatório, mas crítico. Pode se verificar uma estética da violência, nos três contos, devido ao processo segundo o qual a violência é assinalada textualmente, um por trazer o título, construído por meio de um anglicismo, ou seja, a língua do outro, a linguagem do outro, o discurso do 'estrangeiro' (do dominador); outro por trazer a violência no nome da protagonista, e, ainda, outro por meio da estrutura formal que configura o texto em forma de oração, mas rasurada. Percebe-se que há uma importante pista dada ao leitor: a subversão da linguagem por meio da própria linguagem em todos os três textos ficcionais. A estética da violência configura-se, ainda, por meio de escolhas lexicais de vocábulos que pertençam ao campo semântico que remete à violência e do tema, esses elementos que manifestam um sentimento estético.

A violência se estabelece como categoria central na composição dos contos. As três narrativas deslocam o feminino do canto, isto é, do espaço periférico do contexto social para o centro do enredo. Isso demonstra a mudança do foco narrativo que, por muito tempo, visou a figura do dominador (masculino), e agora dirige o olhar para o feminino. As autoras desenvolvem estratégias textuais que permitem esse trânsito, a começar pelos títulos, sendo que dois focalizam a personagem masculina, mas com enredos que se centram nas femininas, outro evidencia um espaço a priori feminino, a casa, mas o caracteriza com um qualificador masculino "dos mastros", e, ainda assim, apesar de a casa ser dos mastros, a protagonista é feminina. Subvertem, desse modo, os três contos, a supremacia masculina no contexto ficcional.

O contexto de violência em que as personagens femininas estão inseridas pontua as estruturas de dominação que são, conforme Bourdieu, produto de um trabalho incessante (e, como tal, histórico) de reprodução, para o qual contribuem agentes específicos (entre os quais os homens, com suas armas como a violência física e a violência simbólica) e instituições como Família, Igreja, Escola, Estado. A contribuição dessas instituições na reprodução de atos violentos evidencia-se, nas ficções em pauta, principalmente por meio da figura do marido, que representa a instituição familiar, e por meio da ideologia da Igreja católica, segundo a qual o casamento é indissolúvel, ainda que se configure como espaço de reprodução de violência (BOURDIEU, 2002). 
Pierre Bourdieu afirma que uma relação desigual de poder comporta uma aceitação dos grupos dominados, não sendo necessariamente uma aceitação consciente e deliberada, mas principalmente de submissão pré-reflexiva (BOURDIEU, 2002). As protagonistas dos contos em análise estão incluídas, como mulheres, no próprio objeto que não conseguem apreender: a dominação masculina, conforme se verifica no fragmento seguinte, retirado do conto "Marido": "Pensou como, para além do sacramento, seria triste a vida de porteira sem um marido [...]" (JORGE, 1998, p. 17). E ainda pode-se verificar a dominação masculina em um trecho extraído do conto "I Love my Husband", conforme segue: "As palavras do homem são aquelas de que deverei precisar ao longo da vida. Não tenho que assimilar um vocabulário incompatível com o meu destino, capaz de arruinar meu casamento" (PIÑON, 1980, p. 65). As personagens protagonistas de ambas as ficções reproduzem modelos de pensamento que são, eles próprios, produtos da dominação masculina.

As marcas culturais das relações de poder concebem o masculino e o feminino, objetiva e subjetivamente, por meio de dicotomias e oposições arbitrárias. A divisão das coisas e das atividades (sexuais e outras) se faz segundo um jogo enraizado numa topologia sexual do corpo socializado (BOURDIEU, 2002). Lídia Jorge marca, no conto em pauta, os lugares masculinos e femininos quando pontua o pensamento de Lúcia, que repete o senso comum sobre o espaço do homem no lar e na sociedade, conforme se lê no fragmento que segue:

E quem atarrachava as lâmpadas do tecto? Quem tinha força para empurrar os móveis? Quem espantava os ladrões de carro com dois tiros para o ar, do alto da varanda? Quem desarmava a cama, empurrava o frigorífico, consertava o carro quando avariava, reclamava o criado com voz grossa quando saíam a comer caracóis à beira-mar? Quem enfrentava os polícias quando na estrada faziam paragem? Quem conduzia e percebia as coisas do carburador? Quem? Quem? (JORGE, 1998, p. 18).

A narradora, imediatamente após esses questionamentos levantados pela porteira, revela uma crítica a esse posicionamento ideológico que considera a figura masculina indispensável na vida de uma mulher, quando afirma ironicamente: "Que papel imprescindível, que pessoa necessária na vida da porteira” (JORGE, 1998, p.18). E, posteriormente a essa crítica sutil, retoma o pensamento de Lúcia, que agora marca o lugar do feminino no lar e na sociedade, conforme segue: "Ela é que o vestia, ela é que determinava a comida, ela é que o mandava pôr os pregos, ir buscar os pombos, alimentar os pombos. [...] E podia entregar-se à devoção" (JORGE, 1998, p. 19).

Também Nélida Piñon busca manter, de modo crítico, porém sutil, a falsa simetria da relação entre o marido e a mulher quando encena, na ficção, o comportamento da protagonista que tenta se "convencer" de que está sendo egoísta em ter perturbado a noite do marido. Ela, então, busca a resignação:

Para esconder minha vergonha, trouxe-lhe café fresco e bolo de chocolate. Ele aceitou que eu me redimisse. Falou-me das despesas mensais. Do balanço da firma ligeiramente descompensado, havia que cuidar dos gastos. Se contasse com a minha colaboração, dispensaria o sócio em menos de um ano (PIÑON, 1980, p. 63).

O lar e a igreja são espaços que reiteram a condição de submissão do feminino nos contos. Devoção, silenciamento e escuridão são formas pelas quais o corpo se submete e se torna, ao mesmo tempo, tão útil e sujeitado (FOUCAULT, 1977). O corpo foi dobrado pelo poder, através de várias técnicas de dominação, nesses casos pela dominação religiosa, marital e paterna que levavam a porteira a ficar "acocorada no trono do pombal" (JORGE, 1998, p. 18), a esposa de "I Love my Husband" a buscar refúgio em um tempo e em um espaço de 
devaneio, e Violete a devorar romances. Essas situações, vivenciadas pelas três protagonistas, retratam a dominação masculina, que seria, para Bourdieu, uma forma particular de violência simbólica (BOURDIEU, 2002).

\section{Considerações finais}

A temática da violência contra a mulher foi observada, neste trabalho, por meio de análise de textos literários curtos. A investigação em torno da forma e do conteúdo dos contos "I Love my Husband", de Piñon, "A casa dos mastros", de Amarílis, e "Marido", de Jorge buscou subsídios para defender que esses discursos, escritos por penas femininas, retidos e fragmentados, aproximam-se porque apresentam forma comprimida de narrar e conteúdo prensado, configurando-se, assim, em retenção da forma e do conteúdo, porque textos femininos sobre a violência.

Os contos de Piñon, de Amarílis e de Jorge suscitam discursos femininos retidos e fragmentados, os quais expressam, no mínimo, duas histórias: de mulheres vítimas de violências simbólica e física, mas, sobretudo, de mulheres mártires do discurso interrompido e do silenciamento. Defende-se, por isso, que a forma comprimida de narrar abarca um conteúdo prensado.

\section{FEMININE WRITINGS: TALES MARKED BY THE NON-SID}

ABSTRACT: Tales written by Nélida Piñon, Orlanda Amarílis and Lídia Jorge, portuguese-speaking women writers, offer a critical approach on discourses and feminine spaces enunciated and staged in Portuguese, language literature of the late twentieth century. The theoretical basis of the work is mainly based on Simone de Beauvoir (1970), on the feminine, in Gayatri Spivak (2010), on the representation of subalternity, in Pierre Bourdieu (2002) on violence.

Keywords: Female. Silencing. Violence.

\section{Referências}

ABDALA JUNIOR, Benjamin. Literatura, história e política. São Paulo: Ática, 1989.

ABDALA JUNIOR. De voos e ilhas: literatura e comunitarismos. São Paulo: Ateliê, 2003.

ALMEIDA, Sandra Regina Goulart. Gênero, identidade, diferença. Aletria: Revista de Estudos Literários. Belo Horizonte, v. 9, n. 1. 2002. Disponível em: http://www.periodicos.letras.ufmg.br/index.php/aletria/article/view/1301. Acesso em: 12 fev. 2015.

AMARÍLIS, Orlanda. A casa dos mastros: contos caboverdianos. Linda-a-Velha: ALAC (Africana), 1989.

BAKHTIN, Mikhail. O discurso no romance. In: Questões de literatura e de estética: a teoria do romance. São Paulo: Hucitec, 1993. p.71-163.

BEAUVOIR, Simone de. O segundo sexo: fatos e mitos. 4. ed., São Paulo: Difusão Europeia do Livro, 1970. v. 1.

BOURDIEU, Pierre. A dominação masculina. Rio de Janeiro: Bertrand do Brasil, 2002.

IPOTESI, JUIZ DE FORA, v.23, n.1, p. 113-120, jan./jun. 2019 
CORTÁZAR, Júlio. Alguns aspectos do conto. In: Valise de Cronópio. São Paulo: Perspectiva, 2006.

DELEUZE, Gilles; GUATTARI, Felix. $O$ anti-Édipo: capitalismo e esquizofrenia. Lisboa: Assírio \& Alvim, 1972.

FOUCAULT, Michel. Vigiar e Punir: nascimento da prisão. Petrópolis: Vozes, 1977.

FOUCAULT, Michel. História da sexualidade: o uso dos prazeres. Lisboa: Relógio d'Água, 1994. v. 2.

ISER, Wolfgang. Os atos de fingir ou o que é fictício no texto ficcional. In: COSTA LIMA, Luiz (org.). Teoria da literatura em suas fontes. Rio de Janeiro: Civilização Brasileira, 2002. v. 2. p. 955-987.

JORGE, Lídia. Marido e outros contos. 2. ed. Lisboa: Dom Quixote, 1998.

LUDMER, Josefina. Literaturas pós-autônomas. Sopro panfleto político-cultural, n. 20, jan. 2010. Disponível em: http://www.culturaebarbarie.org/sopro/outros/posautonomas.html Acesso em: 15 fev. 2018.

PIÑON, Nélida. O calor das coisas: contos. Rio de Janeiro: Nova Fronteira, 1980.

RESENDE, Antônio Martinez de. Latina essentia: preparação ao latim. 2. ed. Belo Horizonte: UFMG, 1996.

SPIVAK, Gayatri Chakravorty. Pode o subalterno falar? Belo Horizonte: UFMG, 2010.

Data de submissão: 27/05/2019.

Data de aceite: $29 / 08 / 2019$. 